\title{
Impacts of Artificial Intelligence on Public Administration: A Systematic Literature Review
}

\author{
João Reis \\ Institute of Social and Political Sciences (ISCSP) and \\ GOVCOPP, University of Lisbon \\ Lisbon, Portugal \\ jcgr@campus.ul.pt
}

\author{
Paula Espírito Santo \\ Institute of Social and Political Sciences (ISCSP) and \\ CAPP, University of Lisbon \\ Lisbon, Portugal \\ paulaes@iscsp.ulisboa.pt \\ Nuno Melão \\ Department of Management and CI\&DETS, School of \\ Technology and Management of Viseu, Polytechnic \\ Institute of Viseu \\ Viseu, Portugal \\ nmelao@estgv.ipv.pt
}

\begin{abstract}
The advent of machines power-driven by Artificial Intelligence (AI) have strongly influenced the world in the $21^{\text {st }}$ century. The future of $A I$ is promising and is offering a wide range of opportunities for scholars and academics. Although the theme has received a considerable attention over the last years, much has been speculated and little is known about its impacts on the Public Administration. Thus, the purpose of this article is to make the result of those impacts less ambiguous. To this end, we have conducted a systematic review to provide a comprehensive analysis on the latest impacts of AI on the Public Administration. Our intent is to narrow the field of study, while AI is being continuously strengthened with new empirical evidences.
\end{abstract}

Keywords - artificial intelligence; systematic literature review; impacts; public administration.

\section{INTRODUCTION}

Most people would agree that comparing humans and machines is not so simple and straightforward - although a computer may not excel in abstract reasoning, it has the ability to handle a large amount of data much faster than a human brain can do [1]. In recent years, researchers and practitioners are investing on the technological potentialities of AI to handle large amounts of public administration data. Artificial intelligence is generally identified as an interdisciplinary research field that gains special attention in society, economics and the public sector, opening up a variety of new opportunities $[2,3,4]$. The global tendency to use AI technologies in many areas of our life, including complex systems in the field of transportation, space, medicine, research, emergency, etc., evokes debates about its use for public administration [5].

The McKinsey Global Institute advances the United States (US) and China as dominant countries in the AI landscape, with Europe falling behind [6]. Accordingly, the White House, the European Parliament and the UK House of Commons, each issued a report outlining their vision on how to prepare the society for the widespread use of AI [7], predicting widereaching changes ahead. In addition, China and the US have recognized the value of AI for the public sector and their competitiveness in the global economy [3]. Likewise, the State
Council of the People's Republic of China has issued a guideline on developing AI, setting a goal of becoming a global innovator in the field, with a total investment of 1 trillion yuan $(\$ 147.8$ billion) by 2030 [8]. If such measures are not already in use, at least some of the elements of AI technologies are already being implemented.

Despite the efforts made and the increased investment in AI research over the last three years [4], there still does not appear to be a broad discussion over the topic on the public sector. Thus, when compared to business areas, the AI in the public sphere is still in its infancy. However, we do acknowledge enough advancements in the area $[9,10,3]$ that allows a reliable evaluation of its impacts. Towards this end, we will not attempt to find new avenues for AI, but we rather discuss its impacts.

This article is organized as follows. In section 2 , we present several introductory concepts. In section 3 , we describe the methodological approach, the selection and analysis of manuscripts. Section 4 discusses the most relevant categories and subcategories that emerged from the literature. We conclude this article by discussing the implications for the theory and practice and future research.

\section{TERMINOLOGY}

Artificial Intelligence and Machine Learning, for instance, are two buzzwords which are often used interchangeably. However, these two terms do not really have the same meaning. In short, AI can be defined as intelligent systems with the ability to think and learn [11]. Today, several techniques fall under the umbrella of AI. Examples of these are: neural networks - the process through which machines learn from observational data, figuring out its own solutions [12]; deep learning - a technique that allows computational models of multiple processing layers to learn and represent data with multiple levels of abstraction mimicking how the brain perceives and understands multimodal information [13]. In light with the above, machine learning is best considered as a subset of AI - the machine can adjust its own algorithm to the situation and "learn", hence the system literally re-codes itself [14]. The aforementioned techniques have achieved outstanding performance on many important 
problems in applications [12], such as: computer vision - which is an algorithmic inspection and analysis of images [15]; natural language processing - an area of research and application that explores how machines can be used to understand and analyse language text or speech used by humans [16]; and speech recognition - that enables devices to recognize, adapt and translate voice information in understandable forms, including e.g. voice user interfaces such as voice dialling [17]. Therefore, AI is the space inhabited by technologies, such as machine learning and language processing - the combination and application of these technologies, such that they attempt to replicate or outperform our own cognition, could be seen as AI [9]. Heinonen et al. [18] shares the same view, and argue that AI has to do with the theory and development of computer systems able to perform tasks normally requiring human intelligence and, machine learning, in turn, is a subset of AI that often uses statistical techniques to give computers the ability to "learn" with data, without being explicitly programmed to do so. Although many of the aforementioned technologies are being used and developed in the business landscape, their applicability to public administration is believed to be viable in short term.

But, how do machines learn? In the human educational sphere, computer simulation, an active learning technique, is now one of the advanced pedagogical technologies used in public administration, public policy and political sciences courses [19]. This technique enables active learning, which means that students actively participate in the learning process. Students play simulation games apart from traditional lectures to gain first-hand understanding of the process of real life. In this respect, Russia has brought some developments to the international scene, in particular as regards with the development of advanced pedagogical techniques in the sphere of public education.

Machines also use similar techniques, as the long-standing goal of AI is an algorithm that learns, tabula rasa, superhuman proficiency in challenging domains [20]. Silver et al. [20] explains that AlphaGo became the first program to defeat a world champion in the game of Go by evaluating positions and selected moves using deep neural networks. In other words, these neural networks are trained by human-supervised learning and self-learning, the latter learning is without data or human guidance and goes beyond game rules - i.e. AlphaGo learns from self-playing.

In turn, we also present a definition of public administration, alongside with other similar terms, such as public management. Generally, considering the occidental democratic countries, public administration is the term traditionally used to define the formal arrangements under which public organizations serve a government, ostensibly in the public interest [21]. The political nature of public administration has taken on sharper focus, especially with the emergence in the last quarter of the twentieth century of the sub-discipline of public management [22]. In the $1980 / 90$ s, the reform of the public sector organizations had gained a significant international attention, often referred to as the New Public Management (NPM) [23]. The NPM generally describes how management techniques from the private sector are being applied to public services [24].

Still, a question remains, how does the AI fits into the public administration? There are several examples where it is evidenced that $\mathrm{AI}$ is improving public organizations. For instance, Kouziokas [25] has applied artificial intelligence techniques for predicting crime spatially in public management in order to promote safety management in public transportation. According to Kouziokas [26], the results have shown a very good prediction accuracy regarding the region with increased density of crime rates.

There are several other AI-technologies, besides the ones that are presented in this paper. The selection of the aforementioned technologies was not made randomly, as we did a preliminary search on Scopus with the keyword "artificial intelligence" in title, abstract, keywords (311,391 hits): the most used keywords were - (artificial) neural networks (29,531), deep learning (including techniques and methods) $(26,050)$, machine learning $(18,543)$, computer vision $(6,458)$, natural language processing (including systems) $(8,441)$, speech recognition (including semantics and linguistic) $(13,476)$, and for that reason this terminology were chosen for our introductory review.

\section{METHODOLOGY}

\section{A. Search strategy}

We have conducted an analysis of a systematically retrieved sample of empirical literature from two different academic databases (namely: ISI Web of Science and Scopus), which are commonly accepted among researchers as leading scientific bibliographic databases. The ISI Web of Science (WoS) database was selected since it provides a detailed set of metadata, which is essential for the analysis (e.g. countries, institutions, dates, citations), while is not readily available in other databases [27]. The multidisciplinary nature of Scopus database had the ability to provide a wider coverage of data, when compared with ISI WoS. Indeed, Scopus indexes a wide range of AI journals (as of March 24 $4^{\text {th }}, 2019$, we found 127 journals currently publishing in the fields of AI in Scimago). This number is surprisingly high, when compared with "business, management and accounting (miscellaneous)" areas that more generalists and includes similar numbers, namely 164 journals.

It would also be worthwhile to source other databases such as IEEE or ACM in similar depth. However, we deliberately decided to reduce the number of database to emphasise transparency and easy reproduction of results, as by Buchanan and Bryman [28], and commonly followed by academics and researchers [29].

We have chosen a systematic literature review because it is "systematic, explicit, and reproducible method for identifying, evaluating, and synthesizing the existing body of completed and recorded work produced by researchers, scholars and practitioners" [30, p.3]. In order to keep ensuring a transparent and replicable process, the authors have conducted a systematic literature following the method of "Preferred Reporting Items for Systematic Reviews and Meta-Analyses" (PRISMA) [31]. According to PRISMA statement, the method helps researchers summarize existing evidence according to an explicit, rigorous, and transparent step-wise process [32].

\section{B. Identification of sources}

The broad search query was constructed as follows: "Artificial Intelligence" AND "Public Administration". The database search was conducted on January $2^{\text {nd }}, 2019$, and yielded over 6,000 hits. We reduced the number of articles for the review 
by limiting the search to the document title, abstract and keywords. We have also included international literature that was published in English, as these publications have avoided wrong interpretations and contributed to international scholarly debate. We did not select a specific time-frame, as it emerged from the search itself. To ensure scientific rigor, the inclusion criteria focused on document type, i.e. peer-reviewed articles, conference papers and their availability in full-text format. After removing duplicates this search led to an initial number of 82 references. In a second phase, we have excluded 1 article that was not available in full-text format and another two that were focused on technical aspects. The remaining 79 references included 18 scientific journals and 61 conference papers. Table 1 shows the methodological approach.

Table 1. PRISMA Flow Chart

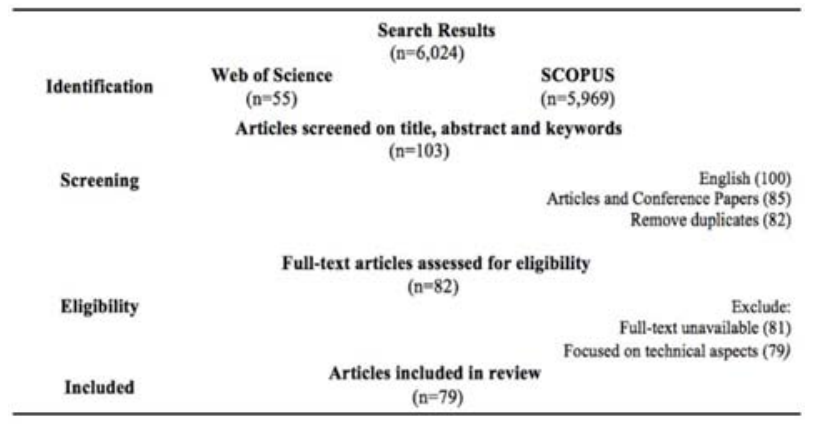

As a next step, the authors read the articles full text and coded the selected research contributions, by clustering the text into categories, to systematize the field of research. To that purpose, we have used a computer-assisted qualitative data analysis software NVivo - QSR International. The result of the content analysis is listed in table 2.

Table 2. Coding scheme for AI impacts on Public Administration

\begin{tabular}{|c|c|c|}
\hline Category & Codes & Articles \\
\hline \multirow[b]{2}{*}{ Jobs } & - Productivity & (Penichet et al., 2008), (Agarwal, 2018) \\
\hline & - Workforce & $\begin{array}{l}\text { (Agarwal, 2018), (Bundin et al., 2018), (Dhanabalan } \\
\text { and Sathish, 2018) }\end{array}$ \\
\hline \multirow{5}{*}{$\begin{array}{l}\text { Political leaders and } \\
\text { public administrators }\end{array}$} & $\begin{array}{l}\text { - Decision-making and } \\
\text { ethics }\end{array}$ & $\begin{array}{l}\text { (Adorni, 2000), (Castellano et al., 2007), } \\
\text { (Sutherland, 2008), (Boselli et al., 2011), (Abbate et } \\
\text { al., 2014), (Agarwal, 2018), (Mikhail et al., 2018), } \\
\text { (Veale et al., 2018) }\end{array}$ \\
\hline & - Energy sector & $\begin{array}{l}\text { (Dhanabalan and Sathish, 2018), (Poolla et al., } \\
\text { 2014), (Sivarajah et al., 2014), (Carli et al., 2015) }\end{array}$ \\
\hline & - Education sector & (Dhanabalan and Sathish, 2018), (Sara et al., 2015) \\
\hline & $\begin{array}{l}\text { - Defence and security } \\
\text { sectors }\end{array}$ & (Dhanabalan and Sathish, 2018) \\
\hline & - Public opinion & (Corallo et al., 2015) \\
\hline \multirow[t]{2}{*}{ Citizens } & - Health and Safety & $\begin{array}{l}\text { (Adorni, 2000), (Triviño et al., 2011), (Shen et al., } \\
\text { 2012), (Stanek and Drosio, 2012), (Stanek and } \\
\text { Drosio, 2014), (Hajek and Olej, 2015), (Dhanabalan } \\
\text { and Sathish, 2018) }\end{array}$ \\
\hline & - Privacy and thrust & $\begin{array}{l}\text { (Agarwal, 2018), (Budin et al., 2018), (Dhanabalan } \\
\text { and Sathish, 2018), (Mikhail et al., 2018), (Xenakis } \\
\text { and Machintosh, 2004) }\end{array}$ \\
\hline
\end{tabular}

The methodological approach presents some limitations, as the literature review is confined to its keywords. Therefore, we admit the possibility of some relevant articles may be missing. To mitigate this limitation, we added some relevant literature in the discussion section of this article to corroborate the arguments of the scholars identified in table 2, but it also seems relevant to reinforce the need for a more critical analysis of the literature in a forthcoming paper. Due to space limitations, it was not possible to list all the references, which may be provided on request by contacting the first author.

\section{FINDINGS}

By analysing the selected manuscripts, we have categorized three core areas that, in our opinion, deserve to be studied. They are jobs, political leaders/public administrators and, finally, the citizens' quality of life. Following, we present a detailed overview of the impacts that AI has on each of those areas.

\section{A. Impacts on jobs}

AI will have a significant impact on jobs and work in ways that were unimaginable a few years ago. The most prolific product of these technologies will be on the transport sector, with the commercialization and proliferation of autonomous vehicles [9]. The general trend to replace public employees by robots is becoming obvious and it could happen soon enough [33]. One of most recent and well-known cases is the use of different expert systems or AI assistants that can, based on the analysis of big data, offer a solution to a practical case [34].

In order to cope up with the problems due to the loss of jobs, the workforce will have to be retained to take up new types of jobs which may emerge with the automation of processes - as people lose their jobs, they will have to be retrained and reemployed [35].

In light with the above, McKinsey Global Institute has published a discussion paper assessing the specific priorities for the Chinese government to strengthen the pipeline of specialized AI talent and to ensure the education system to develop technological skills to large segments of the workforce. We quote $[6$, p. 36]:

1) "to address the China's AI talent gap, the government needs to invest in AI-related education and research programs, reorient the education system for a greater focus on innovation and digital skills, and devise an immigration policy to attract the best global talent" and,

2) "to be proactive identifying the jobs that are most likely to be automated and ensure that retraining programs are made available".

McKinsey Global Institute is therefore advising China to avoid scholars' predictions [36, 37], who are arguing that advanced economies may face high unemployment rates due to technological advancements and human replacement, while poor countries may not afford AI technology or may have limited network access and low educational background to respond to changes through AI technology.

Although public administrators are quite cautious about innovation [34], AI-based public services are emerging, promising great value with regard to workforce and productivity [3]. On the other hand, due to AI rapid advancements, it is difficult for any business or government to keep up with the pace, which is bringing significant challenges to political leaders and public administrators, especially in the education field. As AI can help achieve one of the most prominent dreams of public administration, which is to improve the service quality and simple procedures [38], a comprehensive curricular approach in public universities is needed [35] to prepare private and public sector workers for the future. 


\section{B. Impacts on political leadership and public administrators}

The second research stream focuses on five fields of political leadership and public administrations.

As previously mentioned, the education itself is crucial for growth in several domains, and the net impact of AI in education would be quite high [35]. For instance, Sara et al. [39] have conducted a research to predict high-school dropout with machine learning, since pupils not finishing secondary education are a big societal problem in Denmark.

Another domain is the energy sector. Making energy clean, affordable and reliable has been recognized essential for fighting against several problems including poverty [35]. On that basis, there are several studies that offer valuable insights to public administrations on how AI can be used to address pressing societal challenges such as efficient energy (e.g. renewable energy) use and facilitate better policy making [40, 41]. An example is the development of an Urban Control Centre (UCC), a control room of a smart city that allows public administrators to analyse the city dynamics and citizens to receive information on the performance of urban infrastructure and services, with a specific focus on energy efficiency and environmental sustainability [42].

A third identified domain is the defence and security sector. AI can be leveraged to protect economic sectors and infrastructure, such as airports and power plants that are vulnerable to attacks; along with $\mathrm{AI}$, robots can be used to perform several jobs which are unsafe for humans, such as recovering explosives, detecting mines, to name a few [35]. We are also witnessing the advent of a new era of robots - drones that can autonomously fly in natural and man-made environments; these robots and are often associated with defence applications [43]. However, autonomous weapons systems, controlled by AI and robots, e.g. lethal autonomous weapons systems (hereafter - LAWS) can be debatable from the ethical point of view. If the decision-making algorithm is comparably simple, and ethical issues are not involved, the task to control the machine is simple for a human operator and reasonably she is responsible for the decision [5]. Nevertheless, Mikhail et al. [5] argues that newly developed AI technologies destined for control over complex systems as smart weapons are hardly being fully controlled by a human operator. LAWS can violate fundamental principles of human dignity by allowing machines to choose whom to kill - for example, they might be tasked to eliminate anyone exhibiting "threatening behaviour" [44]. LAWS are stimulating academic debate [45, $46,47,48]$ and will probably raise discussion among policy makers, especially in the legislative sphere $[49,50,51]$. From the practical perspective, the robotics industry, supported by states such as the US, the UK, China, South Korea, and Russia, is currently being developed by dual-use technology and more autonomous weapons systems, meaning that their deployment could become a practical fait accompli in the near future [52].

The fourth field has a connection to public opinion. An example is sentiment analysis, which allows to describe quantitatively the users' opinion of a social network in topics related to public administration. For instance, Corallo et al. [53] aimed to provide reliable estimates and analysis of what citizens thought about institutions, the efficiency of services and infrastructures, the degree of satisfaction about a special event in the context of public administration. These machine learning subsets are based on techniques, such as e.g., natural language processing tools, that enable to establish relationships between the political leaders and its citizens.

The fifth field focuses on decision support systems (DSS). Public administrators have begun to explore DSS very recently [54] and are becoming increasingly competitive in the current scenario in order to be able to analyse large amounts of data from their citizens, i.e. to effectively operate the decision support systems [55, 56]. Public administrators are highly sensitive to these aspects and are looking forward to the availability of DSS allowing for the planning and the definition of areas at risk as well as for the forecasting of possible catastrophic events in order to define the most appropriate intervention and remedial strategies [57]. With the frequent occurrence of emerging incidents in recent years, developing intelligent and effective DSS for emergency response and management is getting crucial to the government and public administration $[58,59]$.

\section{Impacts on the citizens' quality of life}

The aforementioned field brings us up to health and safety domains. Examples of the DSS practice in the field of safety are referred by Stanek and Drosio [60, 61], as computer support for crisis management is today mostly focused on immediate emergency and rescue operations, while there are few all-in-one systems capable of developing support to decision making processes in state administration and at international level. Nevertheless, there may be problems in the decision support. AI machines reflect the bias of their creators or societal biases embedded in the data used to train the machines, as AI learns from data - since our data carry current biases, these machines will only institutionalize such tendencies [9]. Bias or opacity have been exacerbated by the rapidly expanding numbers of data-driven information systems entering the decision-making process [62].

It is the norm that any electronic provider collects data resulting from its interaction or transactions with users and subsequently uses such data to extract value [9]. Processing of information about individuals by AI systems is now not a question - it is a fact [63]. The issues of responsibility and interconnection between the AI machine and its creator could have another implication, as it could be easily presumed that the decision-making algorithms used in AI systems for public administration will be considered as open data [5]. Therefore, in private sector, it is up for an individual to give her consent on data processing or to object it, whereas in the public sector, the use of information technologies is usually prescribed by law and an individual does not have a right to object it as well as the use of AI technologies to process data [34].

Mikhail et al. [5] argues that questions of trust may be raised with AI in decision-making on vital social problems and potentially even the consideration of such decisions on the level of electoral procedures [64]. As AI applications touch several aspects of human life, regulations are needed to ensure safety of the people, protection of privacy, etc. 


\section{CONCLUDING REMARKS}

This article enabled an exploratory categorization of the AI impacts on public administration, which are-impact on jobs, on political leadership and on citizens' quality of life.

It is expected that AI will continue to have a significant impact on public employment. The general trend is to replace public jobs by machines; therefore, the workforce will have to be re-trained and re-employed. Moreover, AI technology itself is taking charge of improving the quality of public education. While we anticipate that AI will bring evident benefits, i.e. cleaner, affordable and reliable energy, there are other controversial issues that are being brought to the academic landscape. The defence area is one example, in particular, the use of drones, as autonomous weapons systems controlled by AI. While these lethal autonomous weapons systems are expected to be able to take a life without a human decision, it raises several ethical and legal issues. In order to assist the political decisions to meet the citizens' expectations, AI may also have a relevant role. In that extent, we have provided some insights concerning the sentiment analysis, which enables measurements techniques on the citizens' opinions, such as the quantification of the citizens' opinion through social networks. In light with the above, DSS are improving decision-making activities and aid public administrators to optimize public services. AI is making a great impact on the citizens' quality of life, namely: on the health and security domains, and on privacy and trust. We have identified AI as supporting crisis management technology, since there are few all-in-one systems capable of developing support to decision making process in state administration. Despite the multiplicity of technological novelties and recipes for their implementation, AI is facing associated challenges regarding the citizens' privacy and trust.

AI is shaping our social life in virtually every country and core areas, such as healthcare, transport or crisis situations. While workers will continue to experience a shift in their roles, focus on the reshape of the public workforce can yield valuable results and provide new avenues for scientific discovery. We also suggest future research to advance the theoretical understanding about the impacts of AI on public administration and to reinforce the arguments of Barth and Arnold [65, p. 349], who have stated "the real danger of AI in government is represented by researchers who are divorced from the world of public administration scholars and practitioners and are engaged in discussions of making technological decisions without understanding the implications for governance of the administrative state". Lastly, it will be eventually relevant to study public administration in the light of political science. Thus, trying to understand the political perspective of the application of AI in public services and the areas of interest from the political point of view.

Although AI in public administration is still giving the first steps when compared with business administration, we suggest a game-changing situation. With the prevalence of empirical studies and a lack of theoretical maturity on AI in the public administration, future research should focus on strengthening the existing theories or developing new ones.

\section{ACKNOWLEDGEMENTS}

This work is financed by national funds through FCT Fundação para a Ciência e Tecnologia I.P., under the project
UID/Multi/04016/2016. Furthermore, we would like to thank the Instituto Politécnico de Viseu and CI\&DETS for their support.

\section{REFERENCES}

[1] J. Stajic, R. Stone, G. Chin, and B. Wible, "Rise of the machines," Science, vol. 349, n. 6245, pp. 248-249, 2015.

[2] M. Boyd, and N. Wilson, "Rapid developments in artificial intelligence: How might the New Zealand government respond?" Policy Quarterly, vol. 13 , n. 4, pp. 36-44, 2017.

[3] B. Wirtz, J. Weyerer, and C. Geyer, "Artificial intelligence and the public sector - Applications and challenges," International Journal of Public Administration, pp. 1-20, 2018.

[4] J. Reis, P. Santo, and N. Melão, "Artificial intelligence in government services: A systematic literature review," World Conference on Information Systems and Technologies, Vol. 932, 2019. DOI: 10.1007/978-3-030-16187-3

[5] B. Mikhail, M. Aleksei, and S. Ekaterina, "On the way to legal framework for AI in public sector," In Proceedings of the $11^{\text {th }}$ International Conference on Theory and Practice of Electronic Governance, pp. 682$684,2018$.

[6] J. Bughin, E. Hazan, S. Ramaswamy, M. Chui, T. Allas, P. Dahlstrom, N. Henke, and M. Trench, "Artificial intelligence - the next digital frontier," McKinsey Glob Institute, 2017.

[7] C. Cath, S. Wachter, B. Mittelstadt, M. Taddeo, and L. Floridi, "Artificial intelligence and the "Good Society": The US, EU and UK approach," Science and Engineering Ethics, vol. 24, n. 2, pp. 505-528, 2018.

[8] State Council of the People's Republic of China, "China issues guidelines on artificial intelligence development," retrieved January 6, 2018, from http://english.gov.cn/policies/latest_releases/2017/07/20/content_281475 742458322.htm

[9] P. Agarwal, "Public administration challenges in the world of AI and Bots," Public Administration Review, vol. 78, n. 6, pp. 917-921, 2018.

[10] J. Corvalán, "Digital and intelligent public administration: Transformations in the era of artificial intelligence," A\&C-Revista de Direito Administrativo \& Constitucional, vol. 18, n. 71, pp. 55-87, 2018.

[11] S. Russell, P. Norvig, and A. Intelligence, "Artificial intelligence: A modern approach,” Englewood Cliffs, NJ: Prentice-Hall, 1995.

[12] M. Nielsen, "Neural networks and deep learning", vol. 25, USA: Determination press, 2015.

[13] A. Voulodimos, N. Doulamis, A. Doulamis, and E. Protopapadakis, "Deep learning for computer vision: A brief review," Computational Intelligence and Neuroscience, 2018.

[14] S. Bini, "Artificial intelligence, machine learning, deep learning, and cognitive computing: What do these terms mean and how will they impact health care?", The Journal of Arthroplasty, 2018.

[15] M. Jarrahi, "Artificial intelligence and the future of work: Human-AI symbiosis in organizational decision making”, Business Horizons, 2018.

[16] A. Reshamwala, D. Mishra, and P. Pawar, "Review on natural language processing," IRACST Engineering Science and Technology: An International Journal (ESTIJ), vol. 3, n. 1, pp. 113-116, 2013.

[17] S. Husnjak, D. Perakovic, and I. Jovovic, "Possibilities of using speech recognition systems of smart terminal devices in traffic environment," Procedia Engineering, vol. 69, pp. 778-787, 2014.

[18] K. Heinonen, J. Kietzmann, and L. Pitt, "AI and Machine Learning in Service Management," Special issue call for papers from Journal of Service Management, Acessed in January $16^{\text {th }}, 2019$, www.emeraldgrouppublishing.com/authors/writing/calls.htm?id=8053.

[19] E. Kutergina, "Computer-based simulation games in public administration education," NISPAcee Journal of Public Administration and Policy, vol. 10, n. 2, pp. 119-133, 2017.

[20] D. Silver, J. Schrittwieser, K. Simonyan, I. Antonoglou, A. Huang, A Guez, T. Hubert, L. Baker, M. Lai, A. Bolton, Y. Chen, T. Lillicrap, F. Hui, L. Sifre, G. Driessche, T. Graepel, and D. Hassabis, "Mastering the game of Go without human knowledge," Nature, vol. 550, n. 7676, pp. 354, 2017. 
[21] J. Johnston, "Public Administration: Organizational Aspects," International Encyclopedia of the Social \& Behavioral Sciences, pp. 12507-12512, 2001.

[22] P. Eisinger, "Public Administration, Politics of," International Encyclopedia of the Social \& Behavioral Sciences, pp. 12512-12515, 2001.

[23] C. Callender, "Public Sector Organizations," International Encyclopedia of the Social \& Behavioral Sciences, pp. 12581-12585, 2001.

[24] J. Lane, "New public management: An introduction,” Routledge, 2002.

[25] G. Kouziokas, "Artificial intelligence and crime prediction in public management of transportation safety in urban environment", In Proceedings of the $3^{\text {rd }}$ Conference on Sustainable Urban Mobility, Volos, Greece, pp. 534-539, 2016.

[26] G. Kouziokas, "An information system for judicial and public administration using artificial intelligence and geospatial data," In Proceedings of the $21^{\text {st }}$ Pan-Hellenic Conference on Informatics, p. 41, ACM, 2017.

[27] F. Brones, M. Carvalho, and E. Zancul, "Ecodesign in project management: a missing link for the integration of sustainability in product development?" Journal of Cleaner Production, vol. 80, pp. 106-118, 2014.

[28] D. Buchanan, A. Bryman, "The Sage Handbook of Organizational Research Methods," Sage publications, 2009.A. Fink, Conducting research literature reviews. From the internet to paper. $3^{\text {rd }}$ ed., London: Sage, 2010.

[29] J. Reis, M. Amorim, and N. Melão, "Multichannel service failure and recovery in a $\mathrm{O} 2 \mathrm{O}$ era: A qualitative multi-method research in the banking services industry," International Journal of Production Economics, 2018. https://doi.org/10.1016/j.ijpe.2018.07.001

[30] A. Fink, Conducting research literature reviews. From the internet to paper. $3^{\text {rd }}$ ed., London: Sage, 2010.

[31] D. Moher, A. Liberati, J. Tetzlaff, and D. Altman, "Preferred reporting items for systematic reviews and meta-analysis: The PRISMA statement," Annals of Internal Medicine, vol. 151, n. 4, pp. 264-269, 2009.

[32] A. Liberati, D. Altman, J. Tetzlaff, C. Mulrow, P. Gotzsche, J. Ioannidis, M. Clarke, P. Devereaux, J. Kleijnen, and D. Moher, "The PRISMA statement for reporting systematic reviews and meta-analyses of studies that evaluate health care interventions: explanation and elaboration," PLoS Medicine, vol. 6, n. 7, e1000100, 2009.

[33] S. Makridakis, "The forthcoming artificial intelligence revolution: Its impact on society and firms," Futures, vol. 90, pp. 46-60, 2017.

[34] M. Bundin, A. Martynov, Y. Aliev, and E. Kutuev, "Legal aspects of the use of AI in public sector," International Conference on Digital Transformation and Global Society, pp. 171-180, Springer, Cham, 2018.

[35] T. Dhanabalan, and A. Sathish, "Transforming Indian industries through artificial intelligence and robotics in industry 4.0," International Journal of Mechanical Engineering and Technology, vol. 9, n. 10, pp. 835-845, 2018.

[36] Aguilera, and M. Ramos, “Technological unemployment: An approximation to the Latin American Case," AD-minister, vol. 29, pp. 5878, 2016.

[37] H. Chen, “AI, e-government, and politics 2.0," IEEE Intelligent Systems, vol. 24, n. 5, 2009.

[38] V. Penichet, M. Tobarra, M. Lozano, J. Gallud, and F. Simarro, “A collaborative Web system to improve citizens-administration communication," In ICEIS, vol. 5, pp. 308-315, 2008.

[39] N. Sara, R. Halland, C. Igel, and S. Alstrup, "High-scool dropout prediction using machine learning: A danish large-scale study," ESANN 2015 proceedings, European Symposium on Artificial Neural Networks, Computational Intelligence and Machine Learning, pp. 319-324, 2015.

[40] U. Sivarajah, H. Lee, Z. Irani, and V. Weerakkody, "Forecasting smart cities through ICT driven policy-making: Expected outcomes and impacts of DAREED project," International Journal of Electronic Government Research, vol. 10, n. 3, pp. 1-18, 2014.

[41] C. Poolla, A. Ishihara, S. Rosenberg, R. Martin, A. Fong, S. Ray, and C. Basu, "Neural networks forecasting of solar power for NASA Ames sustainability base," in Computational Intelligence Applications in Smart Grid, IEEE Symposium on, p. 1-8, 2014
[42] R. Carli, V. Albino, M. Dotoli, G. Mummolo, and M. Savino, "A dashboard and decision support tool for the energy governance of smart cities," in Environmental, Energy and Structural Monitoring Systems, IEEE Workshop on, pp. 23-28, 2015.

[43] D. Floreano, and R. Wood, "Science, technology and the future of small autonomous drones," Nature, vol. 521, n. 7553, p. 460-466, 2015.

[44] S. Russel, S. Hauert, R. Altman, and M. Veloso, "Ethics of artificial intelligence," Nature, vol. 521, n. 7553, pp. 415-416, 2015.

[45] R. Arkin, "Governing lethal behavior in autonomous robots," Chapman and Gall/CRC, 2009.

[46] H. Roff, "The strategic robot problem: Lethal autonomous weapons in war,” Journal of Military Ethics, vol. 13, n. 3, pp. 211-227, 2014.

[47] M. Horowitz, "Public opinion and the politics of the killer robots debate," Research \& Politics, vol. 3, n. 1, 2016.

[48] R. Sparrow, "Robots and respect: Assessing the case against autonomous weapon systems," Ethics \& International Affairs, vol. 30, n. 1, 93-116, 2016.

[49] N. Sharkey, "Saying 'no!' to lethal autonomous targeting," Journal of Military Ethics, vol. 9, n.4, pp. 369-383, 2010.

[50] P. Asaro, "On banning autonomous weapon systems: Human rights, automation, and the dehumanization of lethal decision-making," International Review of the Red Cross, vol. 94, n. 886, pp. 687-709, 2012.

[51] A. Krishnan, "Killer robots: Legality and ethicality of autonomous weapons," Routledge, 2016.

[52] I. Bode, and H. Huelss, "Autonomous weapons systems and changing norms in international relations," Review of International Studies, pp. 1$21,2018$.

[53] A. Corallo, L. Fortunato, M. Matera, M. Alessi, A. Camillò, V. Chetta, E. Giangreco, and D. Storelli, "Sentiment analysis for government: An optimized approach," in International Workshop on Machine Learning and Data Mining in Pattern Recognition, pp. 98-112, Springer, Cham, 2015.

[54] R. Boselli, M, Cesarini, and M. Mezzanzanica, "Framework guidelines to measure the impact of business intelligence and decision support methodologies in the public sector," in Proceedings of the European Conference on e-Government, pp. 107-115, 2011.

[55] M. Castellano, G. Mastronardi, A. Aprile, M. Minardi, P. Catalano, V. Dicensi, and G. Tarricone, "A decision support system base line flexible architecture to intrusion detection," Journal of Software, vol. 2, n. 6, pp. 30-41, 2007.

[56] T. Abbate, C. Bassano, A. Coppola, S. Miranda, and L. Rarità, "A knowledge-based decision support system for the service quality improvement in organizations," in $7^{\text {th }}$ International Workshop of Information Logistics and Knowledge Supply, ILOG, pp. 49-60, 2014.

[57] G. Adorni, "DESIREE: Decision support system for inundation risk evaluation and emergencies management," in International Conference on High-Performance Computing and Networking, pp. 555-557, Springer, Berlin, Heidelberg, 2000.

[58] J. Sutherland, "Directive decision devices: Reversing the locus of authority in human-computer associations," Technological Forecasting and Social Change, vol. 75, n. 7, pp. 1068-1089, 2008.

[59] H. Shen, J. Hu, J. Zhao, and J. Dong, "Ontology based mdeling of emergency incidents and crisis management," in Proceedings of the $9^{\text {th }}$ International ISCREAM Conference, Vancouver, Canada, 2012.

[60] S. Stanek, and S. Drosio, "A Hybrid Decision Support System for disaster/crisis management", in DSS, pp. 279-290, 2012.

[61] S. Stanek, and S. Drosio, "Intelligent computer support for crisis management," Intelligent Decision Technologies, vol. 8, n. 1, pp. 53-63, 2014.

[62] M. Veale, M. Van Kleek, and R. Binns, "Fairness and accountability design needs for algorithmic support in high-stakes public sector decisionmaking," In Proceedings of the 2019 CHI Conference on Human Factors in Computing Systems, ACM, 2018.

[63] A. Costa, V. Julian, and P. Novais, "Personal assitants: Emerging computional technologies," Intelligent Systems Reference Library, vol. 132, Springer, Cham, 2018. 
[64] A. Xenakis, and A. Macintosh, "Trust in public administration etransactions: E-voting in the UK," in International Conference on Trust, Privacy and Security in Digital Business, pp. 162-171, Springer, Berlin, Heidelberg.
[65] T. Barth, and E. Arnold, "Artificial intelligence and administrative discretion: Implications for public administration," The American Review of Public Administration, vol. 29, n. 4, pp. 332-351, 1999. 